\title{
Remembering Bruno Speck
}

The death of Bruno Speck in September of 1998 leaves all of us in the bone marrow transplant field saddened. We have lost a friend and colleague and will miss his presence dearly.

Bruno began his career in bone marrow transplantation in 1969 in Leiden, Holland, where he began a close and lasting friendship with Jon van Rood. He helped found the bone marrow transplantation program in Leiden. Among other accomplishments at Leiden, he was lead author on a manuscript in 1973 describing the first attempt to treat aplastic anemia with bone marrow from a phenotypically matched unrelated donor. While at Leiden he also became interested in the observations of George Mathé that some patients given antilymphocyte globulin and bone marrow infusions improved even though engraftment was transient or not evident. Over the next decade, his laboratory and clinical work established immunosuppression with ATG as an effective treatment for patients with aplastic anemia and this has become a standard alternative to bone marrow transplantation for this disease. Bruno also developed the rabbit as a successful animal model for studying the pathogenesis of aplastic anemia and subsequently his laboratory utilized the rabbit model for other transplantation studies. In 1980, Bruno received the Ernst Jung Award for Medicine for his basic studies on the pathogenesis and treatment of aplastic anemia.

Bruno returned to Switzerland in 1973 to establish one of the first bone marrow transplantation programs in the world in Basel. In addition to his work on aplastic anemia, his program became one of the first to treat leukemia suc-

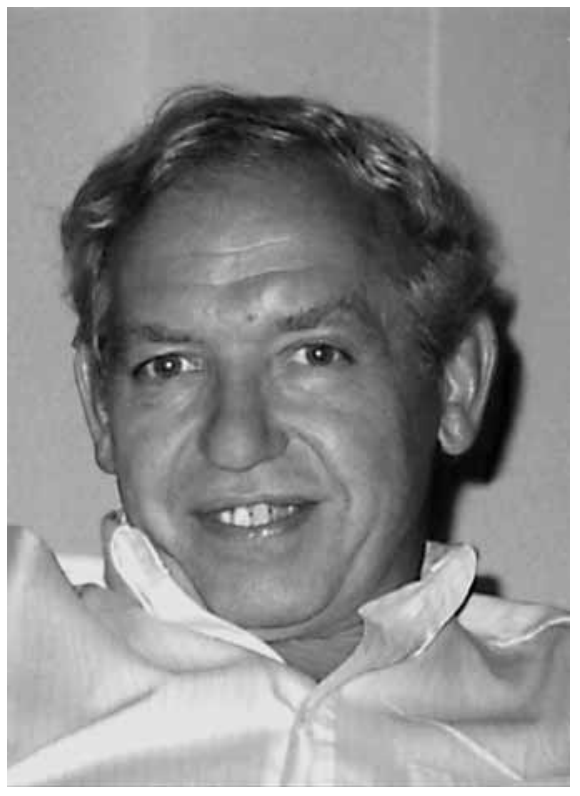

Bruno Speck (1934-1998).

cessfully with bone marrow transplantation. The Basel group were among the pioneers who treated patients with chronic myeloid leukemia in the chronic phase with bone marrow transplantation and who, along with investigators at the Royal Marsden Hospital in London, evaluated cyclosporin for the treatment and prevention of graft-versus-host disease.

One of the major achievements of Bruno Speck was his understanding that progress in bone marrow transplanta-

\section{KARGER}

Fax + 41613061234

E-Mail karger@karger.ch www. karger.com (c) 2000 S. Karger AG, Basel

Accessible online at: www. karger.com/journals/aha 
tion could only be achieved by mutual collaboration. To this end, it was his philosophy and that of Jon van Rood that created the European Group for Blood and Marrow Transplantation (EBMT). He and Jon organized a meeting of active investigators of EBMT (Drs. van Rood, Gluckman, Bussel, Zwaan, Vossen and Cornu) in St. Moritz in 1975. This meeting led to the establishment of the EBMT which has become a major force in the bone marrow transplantation field. The EBMT now includes over 2,500 members and is a tribute to Bruno's foresight.
As Director of Hematology, Kantonsspital Basel, since 1979, Bruno was also responsible for day-to-day activities of a large hematology department. He was esteemed by all of his colleagues and trained a number of investigators, teachers and practitioners throughout Switzerland and the world. All of us who have known Bruno will remember him not only for his skills as a clinician and researcher but also for his warm personality and his positive attitude to life. We all owe a lot to Bruno.

C. Dean Buckner, MD, Seattle, Wash. 